\title{
KAJIAN AWAL PENDUGAAN AKUIFER AIR TANAH DI KAMPUS ITERA DENGAN METODE GEOLISTRIK KONFIGURASI SCHLUMBERGER
}

\author{
Muhamad Ragil Setiawan ${ }^{1}$, Rizty Maulida Badri ${ }^{1}$, Alamta Singarimbun ${ }^{2}$ \\ ${ }^{1}$ Jurusan Sains, Prodi Fisika, Institut Teknologi Sumatera, Lampung, Indonesia \\ ${ }^{2}$ Departemen Fisika, FMIPA, Institut Teknologi Bandung, Bandung, Indonesia
}

\begin{abstract}
:
Air bersih menjadi kebutuhan dasar yang harus disediakan di Institut Teknologi Sumatera (ITERA). Kondisi geologis ITERA berada pada daerah dengan batuan piroklastik di atasnya, batuan tersebut memiliki sifat semipermeabel. Hal ini meyebabkan air di permukaan sukar mengalir ke bawah permukaan. Oleh karena itu, dilakukan kajian awal bawah permukaan dengan melakukan pengukuran sifat kelistrikan batuan menggunakan metode geolistrik konfigurasi Schlumberger untuk mencari potensi air bersih di ITERA. Data hasil pengukuran diolah dengan menggunakan Ms. Excel dan dimodelkan menggunakan software IPI2win. Hasil interpretasi menunjukkan bahwa potensi sumber air ditemukaan berada pada kedalaman > 25 meter dengan rentang nilai resistivitas antara 2 - $10 \Omega m$ dan termasuk ke dalam akuifer tertekan.
\end{abstract}

Keyword: Akuifer, Air tanah, Geolistrik, konfigurasi Schlumberger, IPI2win

\section{Pendahuluan}

Institut Teknologi Sumatera (ITERA) merupakan sebuah institusi pendidikan tinggi negeri baru di provinsi Lampung. Sebagai kampus negeri yang sedang berkembang berbagai sarana dan prasarana dipersiapkan guna mendukung kegiatan belajar mengajar agar berjalan dengan lancar. Infrastruktur seperti gedung kuliah, kantor, laboratorium, sarana olahraga, dan asrama mahasiswa sedang dipersiapkan untuk mahasiswa. Pembangunan fisik yang masif tersebut bertujuan untuk mengimbangi jumlah mahasiswa yang semakin bertambah. Setelah penerimaan tahun 2016 sebanyak \pm 1200 mahasiswa, pada tahun 2017 ITERA merencanakan penerimaan mahasiswa sebanyak \pm 1700 mahasiswa ${ }^{[1]}$. Penerimaan jumlah mahasiswa sebanding dengan peningkatan kebutuhan air bersih di kampus.

Kajian geologis diperoleh informasi bahwa kampus ITERA berdiri di atas lapisan batuan piroklastik. Batuan ini memiliki karakteristik semipermeabel, sehingga air permukaan sukar diteruskan ke bawah permukaan menuju lapisan akuifer ${ }^{[2]}$. Hal ini akan berdampak pada cadangan air di dalam akuifer. Selain itu, berdasarkan pengeboran sumur yang sudah dilakukan, akuifer air tanah di kampus ITERA termasuk akuifer dalam. Kedalaman pengeboran rata-rata $>70 \mathrm{~m}$ di bawah permukaan tanah. Sehingga diperlukan pengukuran guna mengetahui kondisi bawah permukaan.

Salah satu metode geofisika yang dapat digunakan untuk mengetahui kondisi bawah permukaan adalah metode geolistrik. metode ini sudah banyak digunakan untuk mengetahui kondisi bawah permukaan baik secara lateral maupun vertikal. Metode ini digunakan dalam studi lingkungan seperti studi pencemaran air lindi pada daerah di sekitar tempat pembuangan sampah akhir[3][4], studi intrusi air laut ${ }^{[5]}$. Dalam studi geoteknik digunakan dalam identifikasi patahan ${ }^{[6]}$. Adapun dalam zonasi sebaran air tanah 1-D sudah pernah dilakukan di Kecamatan Pinggir, Riau ${ }^{[7]}$. 
Berdasarkan latar belakang di atas, dilakukan penelitian untuk mengetahui kondisi bawah permukaan, mengetahui posisi dan kondisi akuifer di bawah permukaan kampus ITERA. Penelitian dilakukan dengan menggunakan metode geolistrik konfigurasi Schlumberger.

\section{Metode Eksperimen}

\subsection{Pengambilan data}

Lokasi penelitian berada di kampus ITERA dan terletak antara $5^{0} 22$ '06.23" Lintang Selatan dan 105018'20.38" Bujur Timur dengan luas wilayah 285 hektar (gambar 1). Pengambilan data geolistrik dilakukan dengan menggunakan teknik sounding atau vertical electrical sounding (VES). VES biasa digunakan dalam pengukuran data geolistrik dengan target berada pada posisi yangdalam. Hal ini dikarenakan teknik ini memiliki jangkauan penetrasi yang dalam.Titik-titik sounding yang digunakan pada kajian awal ini berjumlah 4 buah titik (warna merah) dengan jarak masing-masing titik sejauh 100 meter. Keempat titik sounding tersebut terdiri atas 3 buah titik yang segaris dan satu buah titik di dekat sumur artesis. Penentuan tiga titik yang segaris berdasarkan target penampang lapisan batuan secara 2-dimensi.

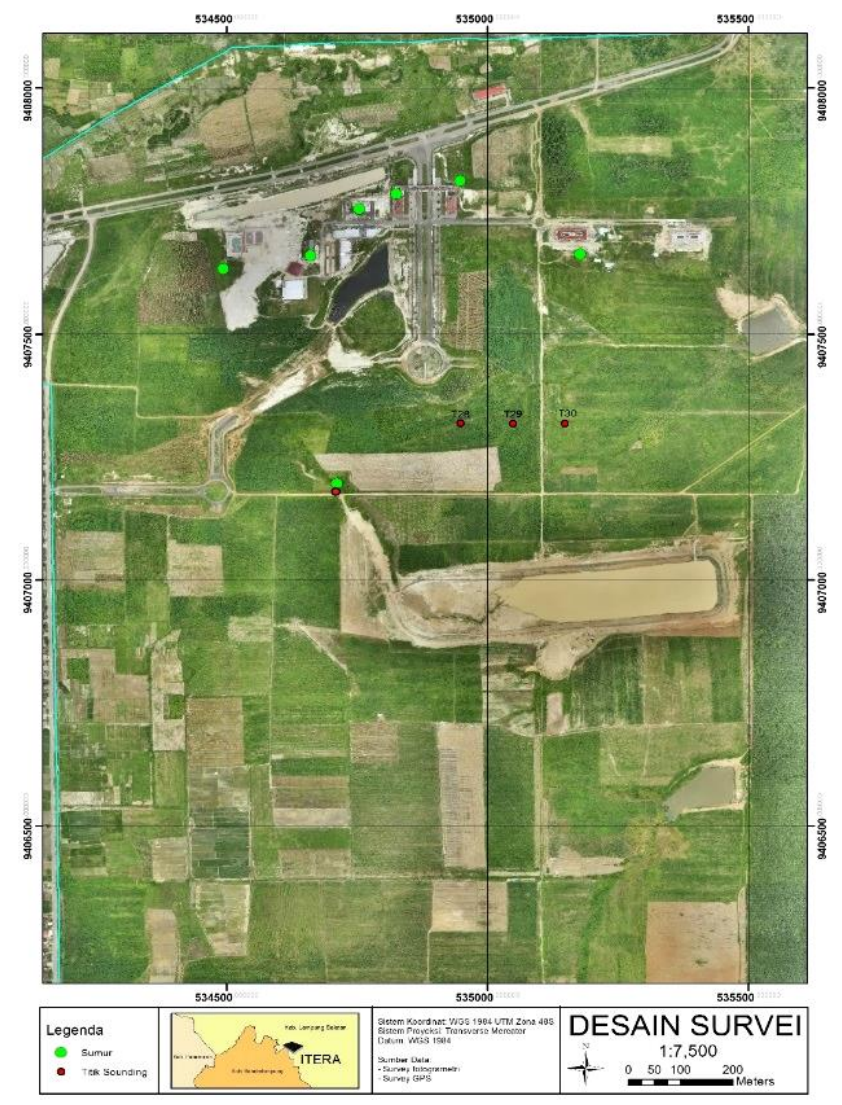

Gambar 1 Daerah penelitian dan posisi titik-titik sounding (titik merah)

Pengukuran titik-titik sounding menggunakan panjang bentangan sebesar 600 meter untuk setiap titik sounding. Posisi titik-titik sounding dapat dilihat pada tabel 1. Masing-masing titik sounding memiliki nilai topografi yang hampir sama.

Tabel 1 Koordinat titik sounding (VES)

\begin{tabular}{|c|c|c|}
\hline Titik sounding & Koordinat & Elevasi \\
\hline T28 & $5^{\circ} 21^{\prime} 42.97^{\prime \prime}$ LS dan $105^{\circ} 18^{\prime} 55.59^{\prime \prime} \mathrm{BT}$ & $111 \mathrm{~m}$ \\
\hline T29 & $5^{\circ} 21^{\prime} 42.98^{\prime \prime}$ LS dan $105^{\circ} 18^{\prime} 58.84^{\prime \prime} B T$ & $101 \mathrm{~m}$ \\
\hline T30 & $5^{\circ} 21^{\prime} 42.99^{\prime \prime}$ LS dan $105^{\circ} 19^{\prime} 2.09^{\prime \prime} \mathrm{BT}$ & $100 \mathrm{~m}$ \\
\hline Sumur & $5^{\circ} 21^{\prime} 47.19^{\prime \prime}$ LS dan $105^{\circ} 18^{\prime} 48.01^{\prime \prime B T}$ & $106 \mathrm{~m}$ \\
\hline
\end{tabular}


Pengambilan titik sounding didasarkan pada informasi kedalaman sumur bor yang sudah pernah dibuat, bahwa air pada umumnya baru ditemukan rata-rata pada kedalaman 100 meter (Tabel 2). Informasi tersebut menjadi dasar penggunaan panjang bentangan kabel.

Tabel 1 Data kedalaman sumur dan kondisinya
\begin{tabular}{|c|l|c|l|}
\hline No & Letak & Kedalaman & Status \\
\hline 1 & Belakang asrama 1 & $120 \mathrm{~m}$ & Masih digunakan \\
\hline 2 & Belakang ruang kontrol gedung B & $100 \mathrm{~m}$ & Tidak digunakan \\
\hline 3 & Samping gedung A & $100 \mathrm{~m}$ & Masih digunakan \\
\hline 4 & Parkiran & $40 \mathrm{~m}$ & Masih digunakan \\
\hline 5 & Depan musholla Baitul 'Ilmi & $100 \mathrm{~m}$ & Masih digunakan \\
\hline 6 & Lapangan basket & $100 \mathrm{~m}$ & Masih digunakan \\
\hline 7 & Sumur tua & $3 \mathrm{~m}$ & Masih digunakan \\
\hline
\end{tabular}

\subsection{Perhitungan nilai resistivitas dan kedalaman lapisan batuan}

Pada metode geolistrik, arus listrik diinjeksikan ke dalam tanah dan menyebabkan munculnya beda potensial yang akan diukur di permukaan. Adanya perbedaan nilai potensial yang terukur dipermukaan menunjukkan ketidaksamaan nilai konduktivitas tanah dalam menghantarkan arus listrik. Nilai konduktivitas memiliki hubungan dengan nilai hambatan jenis dalam suatu penghantar.

$$
\rho=\frac{\delta R \delta A}{\delta L}
$$

dengan $\rho$ merupakan nilai rapat jenis yang berkaitan dengan sifat fisis kelistrikan yang dimiliki oleh suatu material.

Beberapa mineral atau material seperti bahan metal dan grafit merupakan penghantar arus listrik. Keberadaan mineral tersebut di dalam tanah yang memiliki sifat insulator menyebabkan perbedaan daya hantar lapisan tanah di bawah permukaan. Arus listrik di lapisan bawah permukaan dihantarkan oleh ion-ion yang mengalir melalui melalui air yang berada di porositas tanah.

Apabila lapisan tanah digambarkan sebagai sebuah elemen penghantar arus listri, maka hubungan nilai resistivitas dan potensial berdasarkan hukum Ohm,

$$
\delta V=I \delta R
$$

Apabila persamaan (1) disusbtitusikan ke persamaan (2), akan diperoleh

$$
\begin{aligned}
& \delta V=I \frac{\rho \delta L}{\delta A} \\
& \rho=\frac{\delta V \delta A}{I \delta L}
\end{aligned}
$$

Hasil pengukuran di lapangan diperoleh nilai arus (I) dan potensial (V). Berdasarkan kedua nilai tersebut dapat dihitung nilai hambatan $(R)$ yang mengalir diantara elektroda arus dan potensial yang melalui lapisan tanah di bawah permukaan. Nilai hambatan yang diperoleh kemudian dikalikan dengan nilai konstanta konfigurasi (k) yang diperoleh melalui perhitungan teroritis sehingga didapatkan nilai hambatan jenis semu ( $\rho_{a p p a r e n t}$ ). Nilai $\rho_{a p p a r e n t}$ ini kemudian dihitung logaritmiknya dan diplot ke dalam kurva.

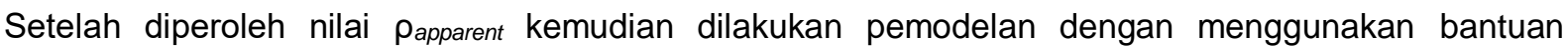
perangkat lunak IPI2win. Perangkat ini dijalankan dengan memasukkan nilai spasi elektroda potensial dan arus, arus, potensial, konstanta konfigurasi, dan hambatan jenis semu. Setelah semua data terbaca oleh program, maka dilakukan forward modeling dan diperoleh kurva hambatan jenis sebagai fungsi jarak. Langkah selanjutnya dilakukan picking kurva teoritis dengan metode curve matching ${ }^{[8]}$ dan mencari nilai kesalahan terkecil $(<10 \%)$ antara kurva pengukuran dan kurva perhitungan. Setelah diperoleh nilai kesalahan terkecil dilakukan inverse modeling dan didapatkan nilai kedalaman dan hambatan jenis batuan pada kedalaman tersebut. Nilai hambatan jenis tersebut kemudian dicocokkan dengan nilai hambatan jenis batuan yang sudah diketahui untuk melakukan interpretasi geologi bawah permukaan. 


\section{Hasil dan Pembahasan}

\subsection{Kondisi geologi daerah penelitian}

Geologi regional batuan permukaan di lokasi penelitian merupakan formasi lampung yang tersusun oleh tufa, batu lempung tufan dan batu pasir tufan. Dari hasil pemetaan geologi dilokasi penelitian menunjukan adanya sebaran batuan yaitu pasirtuff yang terdapat di permukaan. Berdasarkan hasil sifat fisik batuan tersebut merupakan formasi batuan yang dapat menyimpan air namun tidak dalam jumlah yang cukup besar. Hal ini dapat menjelaskan bahwa secara hidrogeologi daerah penyelidikan termasuk kelompok akuifer dengan aliran melalui celah dan ruang antar butir, termasuk akuifer dengan produktifitas rendah namun keterdapatan air tanah dalam jumlah terbatas masih dapat diperoleh karena dilihat dari penyebaran akuifernya cukup luas.

\subsection{Nilai resistivitas dan kedalaman batuan}

Pengolahan nilai resistivitas untuk masing-masing titik VES dengan menggunakan metode curve matching ditunjukkan oleh gambar 2. Sedangkan posisi kedalaman lapisan batuan, jenis lapisan batuan dan nilai resistivitasnya ditunjukkan pada tabel 3, 4, 5, dan 6 .

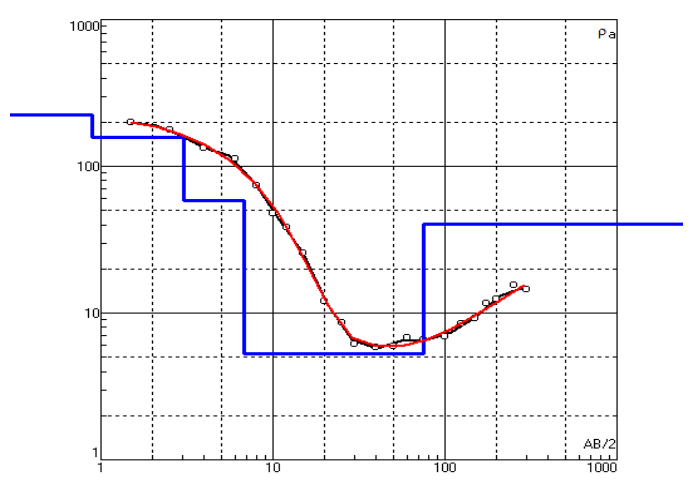

(a)

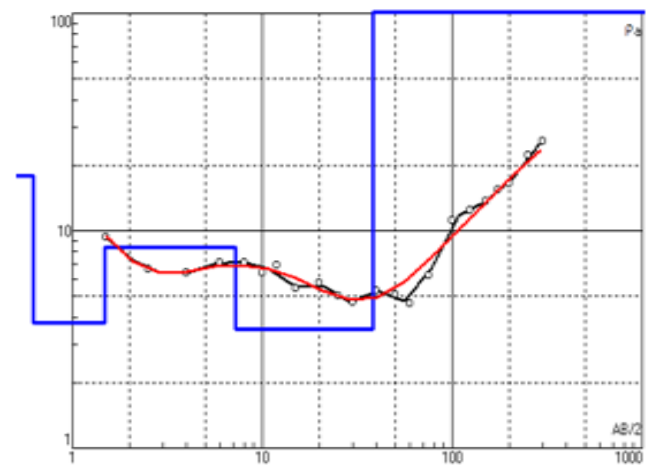

(c)

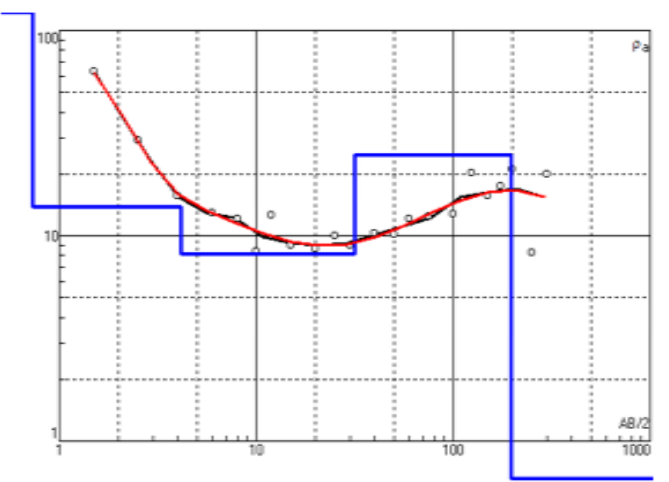

(b)

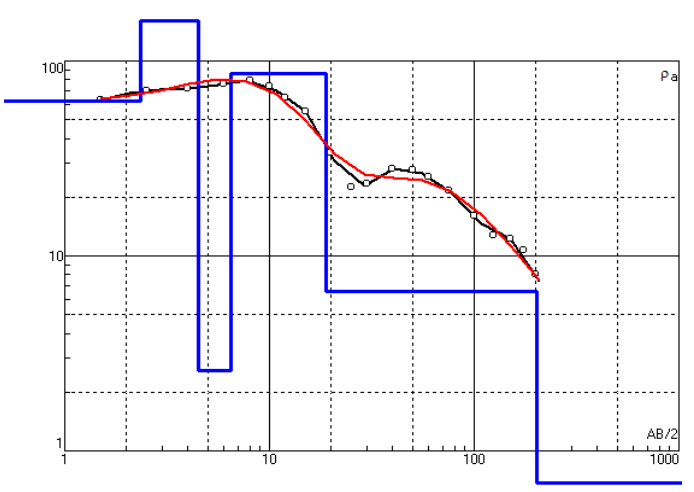

(d)

Gambar 2 Curve matching titik T28 (a), T29 (b), T30 (c), dan sumur (d)

Tabel 3 Dugaan lithologi batuan penyusun pada titik T28

\begin{tabular}{|c|c|c|c|c|}
\hline Lapisan & Kedalaman $(\mathrm{m})$ & Tebal $(\mathrm{m})$ & Tahanan Jenis $(\Omega \mathrm{m})$ & Jenis lithologi \\
\hline 1 & $0,8-3$ & 2,1 & 223 & batu pasir \\
\hline 2 & $3-6,8$ & 3,7 & 157 & lanau \\
\hline 3 & $6,8-74 ., 7$ & 67,9 & 58,4 & lempung \\
\hline 4 & 74,7 & Tidak diketahui & 5,31 & air tanah \\
\hline
\end{tabular}


Tabel 4 Dugaan lithologi batuan penyusun pada titik T29

\begin{tabular}{|c|c|c|c|c|}
\hline Lapisan & Kedalaman $(\mathrm{m})$ & Tebal $(\mathrm{m})$ & Tahanan Jenis $(\Omega \mathrm{m})$ & Jenis lithologi \\
\hline 1 & $0,7-4,1$ & 3,4 & 122 & batu pasir \\
\hline 2 & $4,1-31,6$ & 27,5 & 13,9 & lanau \\
\hline 3 & $31,6-196$ & 164 & 8,11 & air tanah \\
\hline 4 & 196 & Tidak diketahui & 24,8 & lempung \\
\hline
\end{tabular}

Tabel 5 Dugaan lithologi batuan penyusun pada titik T30

\begin{tabular}{|c|c|c|c|c|}
\hline Lapisan & Kedalaman $(\mathrm{m})$ & Tebal $(\mathrm{m})$ & Tahanan Jenis $(\Omega \mathrm{m})$ & Jenis lithologi \\
\hline 1 & $0,6-1,4$ & 0,8 & 17,8 & lanau \\
\hline 2 & $1,4-7,1$ & 5,7 & 3,7 & lempung \\
\hline 3 & $7,1-38,2$ & 31 & 8,4 & batu pasir \\
\hline 4 & 38,2 & Tidak diketahui & 3,5 & lempung \\
\hline
\end{tabular}

Tabel 6 Dugaan lithologi batuan penyusun pada titik Sumur

Tabel 6 Dugaan lithologi batuan penyusun pada titik Sumur
\begin{tabular}{|c|c|c|c|c|}
\hline Lapisan & Kedalaman $(\mathrm{m})$ & Tebal $(\mathrm{m})$ & Tahanan Jenis $(\Omega \mathrm{m})$ & Jenis lithologi \\
\hline 1 & $0,6-1,4$ & 0,8 & 17,8 & lanau \\
\hline 2 & $1,4-7,1$ & 5,7 & 3,7 & lempung \\
\hline 3 & $7,1-38,2$ & 31 & 8,4 & batu pasir \\
\hline 4 & 38,2 & Tidak diketahui & 3,5 & lempung \\
\hline
\end{tabular}

Hasil penampang 1-dimensi pada ketiga titik sounding (VES), yakni T28, T29, dan T30 diolah kedalam bentuk penampang 2-dimensi agar dapat dengan mudah diinterpretasikan. Penampang 2-D yang dihasilkan ditampilkan pada gambar 3. 


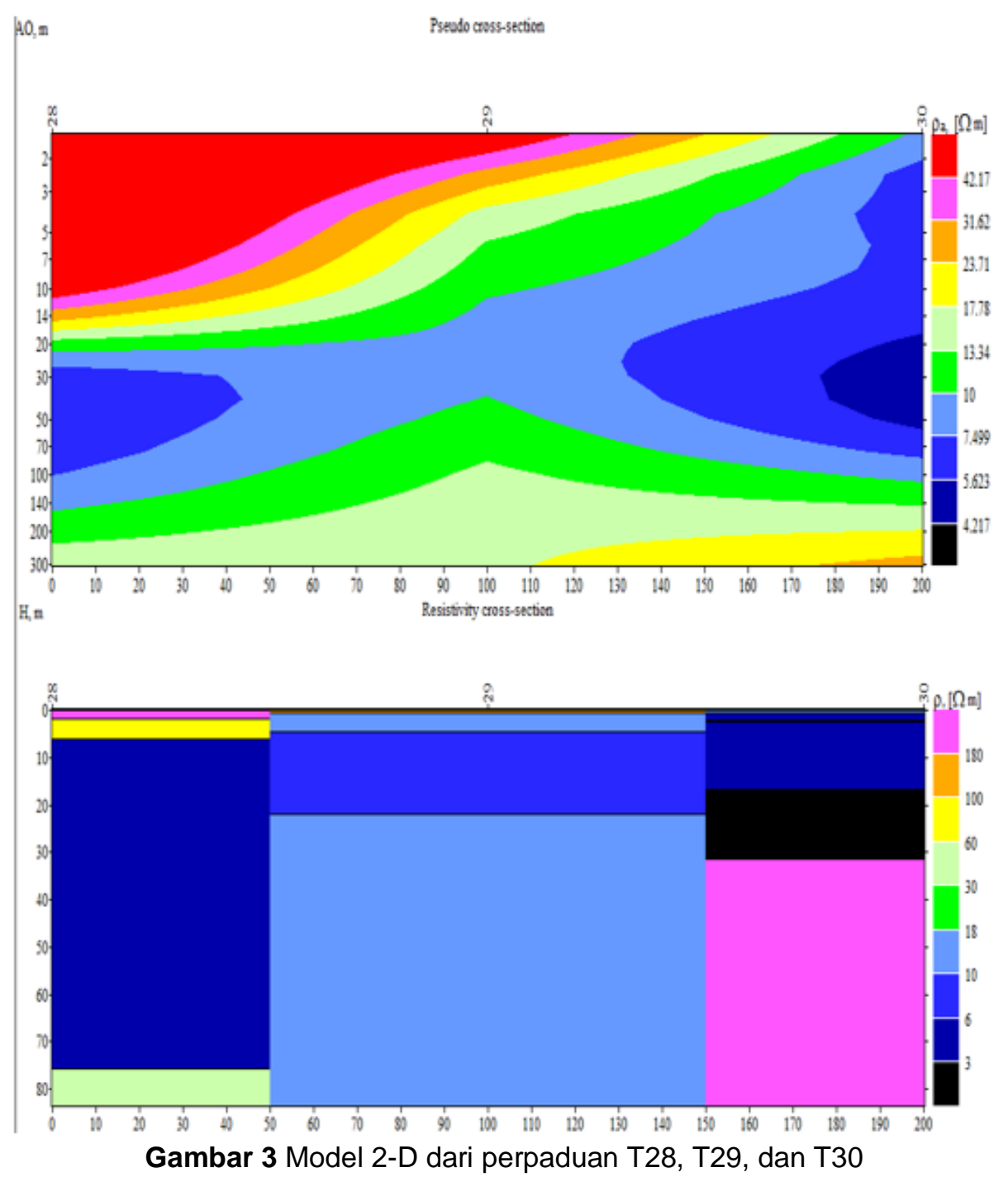

Gambar 3 merupakan representasi lithologi dari penggabungan tiga titik sounding (T28, T29, dan T30) sumbu vertikal mewakili kedalaman $(\mathrm{m})$ dan citra berwarna mewakili besarnya resistivitas $(\Omega \mathrm{m})$. Lapisan akuifer dapat ditentukan dengan melihat keberlanjutan atau keselarasan lapisan satu dengan lapisan yang lain ketika nilai resistivitasnya kontinyu, sehingga aliran yang diduga akuifer dapat ditentukan dan menjadi pertimbangan dalam pengeboran.

Pemodelan pada Gambar 3 merupakan hasil interpretasi data penelitian yang didapatkan setelah dilakukan kross korelasi antara sumur dan koreksi ketinggian pada titik pengukuran. Pada kross korelasi sumur tesebut diinterpretasikan dengan warna yang merepresentasikan formasi batuan pada range nilai resistivitas ${ }^{[9]}$ pada lapisan batuan di masing-masing titik pengukuran. Lapisan paling atas dengan citra warna merah sampai merah muda pada kedalaman 1-12 meter yang memiliki ketebalan $\leq 11$ meter dan nilai resistivitas sebesar 31,6-42,1 $\Omega$ m diduga merupakan lapisan batu pasir yang dapat menyimpan dan mengalirkan air. Lapisan berwarna oranye hingga kuning pada kedalaman $13-$ 18 meter yang memiliki ketebalan $\leq 5$ meter dan nilai resistivitas sebesar 17,2 - 23,7 $\Omega \mathrm{m}$ diduga merupakan lapisan lanau yang dapat menyimpan dan dapat mengalirkan air tetapi dalam jumlah terbatas. Lapisan berwarna hijau pada kedalaman 19-23 meter yang memiliki ketebalan $\leq 4$ meter dan pada kedalaman 150 - 300 meter dengan ketebalan 150 meter memiliki nilai resistivitas sebesar $10-15,8 \Omega m$ diduga merupakan lapisan lempung yang bersifat akuiklud atau sering disebut sebagai lapisan impermeable atau lapisan kedap air. Lapisan berwarna biru yang berada pada kedalaman 1 149 meter dan memiliki ketebalan $\leq 148$ meter dengan nilai resistivitas sebesar 4,2-7,4 $\Omega m$ diduga merupakan lapisan air tanah.

Pada T28 dan T29 air yang terkandung pada lapisan berwarna biru tidak dapat mengalir dengan mudah karena diapit oleh dua lapisan impermeabel. Lapisan berwarna biru dapat dikatakan sebagai 
lapisan akuifer tertekan. Lapisan ini cukup baik karena terdapat lapisan impermeabel pada bagian atas dan bawahnya. Lapisan ini memiliki kadar air yang tinggi. Sehingga pada T28 dan T29 dapat dipertimbangkan untuk melakukan pengeboran. Pada T30 lapisan berwarna biru di duga sebagai air tanah dangkal. Air tanah dangkal memungkinkan memiliki tekanan air yang rendah karena kurangnya batuan penimbun diatasnya yang menyebabkan aliran air menjadi lemah dan kurang terdorong.

\section{Kesimpulan}

Berdasarkan pembahasan di atas, maka dapat ditarik kesimpulan bahawa lithologi batuan di daerah penelitian pada titik pengukuran pada umumnya memiliki jenis yang sama, yaitu lapisan batu pasir, lanau, lempung, dan lapisan diduga akuifer. Akuifer air tanah diperkirakan berada pada kedalaman lebih dari 25 meter dengan rentang nilai resistivitas lapisan batuan antara $2-20 \Omega \mathrm{m}$. Jenis akuifer yang ada di lokasi penelitian termasuk ke dalam akuifer tertekan dengan pembebanan di atas lapisan akuifer berupa batuan penimbun. Pendugaan posisi akuifer akan dapat lebih rinci apabila dilakukan penelitian tambahan dengan menggunakan metode Induced Polarization (IP). Hal ini dikarenakan metode ini sangat baik dalam membedakan nilai resistivitas batuan lempung dan akuifer.

\section{Penghargaan}

Hibah Penelitian Mandiri ITERA 2017.

\section{Daftar Pustaka}

[1] http://usm.itera.ac.id/, diakses pada tanggal 2-03-2017.

[2] Aghazadeh, M. \& A., A. Mogaddam, Investigation of Hydrochemical Characteristics of Groundwater in the Harzandant Aquifer, Northwest of Iran, Springer, Environ Monit Assess, DOI 10.1007/s10661-010-1575-4, 2010.

[3] Ngadimin, Aplikasi Metode Geolistrik untuk Alat Monitoring Rembesan Limbah, JMS Vol. 6 No. 1, 43-53., 2001.

[4] Yudistira, T., dan Hendra G., Pencitraan Konduktivitas Bawah Permukaan dan Aplikasinya untuk Identifikasi Penyebaran Kontaminasi Cair, Geoforum HAGI, 2003.

[5] Santoso, T., Nurul P., dan Puguh H., Pendugaan Intrusi Air Laut dengan Metode Geolistrik Resistivitas 1-D di Pantai Desa Sumberejo Jember, Berkala Saintek Vol. 1 No. 1, 17, 2013.

[6] Utiya, J., As'ari dan Seni HJ. T., Metode Geolistrik Resistivitas Konfigurasi Wenner-Schlumberger dan Konfigurasi Dipole-dipole untuk Identifikasi Patahan Manado di Kecamatan Paaldua Kota Manado, Jurnal Ilmiah Sains Vol. 15 No. 2, 135-141, 2015.

[7] Edisar, M., Pemetaan Zonasi Air Bawah Tanah di Kecamatan Pinggir Kabupaten Bengkalis Provinsi Riau, Prosiding Semirata FMIPA UNILA, 2013, 405-408..

[8] Kearey, P., Michael B., Ian H., An Introduction to Geophysical Exploration $3^{\text {rd }}$ Edition, Blackwell Science, 2002.

[9] Telford, W., L. Geldart, R. Sheriff, Applied Geophysics $2^{\text {nd }}$ Edition, Cambridge, Cambridge University Press, 1990. 